\title{
LAS TECNOLOGÍAS DISRUPTIVAS PARA LAS CIENCIAS ECONÓMICAS, CONTABLES Y ADMINISTRATIVAS
}

Las nuevas tecnologías de información representan un cambio disruptivo para las ciencias económicas, contables y administrativas, debido a que están modificando la forma en que se relacionan los actores de un proceso, la forma en que se generan valor y ventajas competitivas.

Las empresas enfrentan una multitud de oportunidades de negocios como consecuencia directa de múltiples desarrollos tecnológicos disruptivos. Como característica básica, las tecnologías disruptivas conducen a un cambio severo en las redes de creación de valor, dando lugar a nuevos segmentos de mercado (Amshoff et al., 2015). Es entonces cuando tiene relevancia la "tecnología disruptiva o innovación disruptiva", la cual provoca un trastorno en la estructura de mercado existente al ser más simples y más convenientes que la tecnología dominante (Schuelke-Leech, 2018).

Las tecnologías disruptivas son aquellas cuyos atributos difieren de la valoración histórica, y eventualmente penetran en mercados establecidos a través de mejoras rápidas (Hui et al., 2016). En 1995, Clayton Christensen usó el término "tecnología disruptiva" para describir cualquier tipo de innovación que crea resistencia cuando los

1 Tecnología disruptiva: es una tecnología que cambia las bases de la competencia al cambiar las métricas de rendimiento a lo largo de las cuales compiten las empresas (Bower, Christenson, 1995; Danneels, 2004). 
adoptantes potenciales se resisten a la idea del cambio y las tecnologías competidoras luchan contra la posibilidad de ser reemplazadas (Bower, Christenson, 1995). En realidad, existen dos niveles de tecnologías disruptivas: interrupciones de primer orden y de segundo orden. Las interrupciones de primer orden son el foco de una importante literatura sobre negocios e innovación. Las de segundo orden son más amplias y son el resultado de la agrupación de numerosas interrupciones (Schuelke-Leech, 2018).

Se está, entonces, en presencia de una era de transformación dramática donde las tecnologías emergentes constituyen los factores más disruptivos para dar un salto en la gestión del talento, por lo que las empresas deben tomar decisiones estratégicas con un impacto en toda la infraestructura en lugar de mejoras aisladas que afectan únicamente a las funciones o ubicaciones individuales (Brophy, 2015) (Alba, 2020).

Ante este nuevo panorama, desde la Facultad de Contaduría Pública de la Universidad Externado de Colombia se participa en un conjunto de proyectos como son: la participación en la colección Así habla el Externado, con tres capítulos que permiten detectar diferentes posturas desde el derecho, la contabilidad y la administración. Asimismo se extiende la invitación a nuestros lectores para participar en el V Encuentro Internacional de Contabilidad y Gestión organizado por la Facultad de Contaduría Pública de la Universidad Externado de Colombia, el cual tiene presencia todos los años en el mes de noviembre; el encuentro del año 2020 tendrá como tema central las tecnologías disruptivas.

Por otro lado, presento el número 27 de la Revista Apuntes Contables, que cuenta con la presencia de países como Perú, México, Ecuador y Colombia, los cuales, desde el análisis de las finanzas, los costos, el control interno, los impuestos, el emprendimiento, la innovación y la corrupción garantizan a nuestros lectores e investigadores la actualización constante. Sea este el momento de agradecerles a todos los participantes en este número: autores, pares evaluadores, asistente editorial y al Departamento de Publicaciones de la Universidad Externado de Colombia porque gracias a ustedes la revista se publica de manera anticipada y cada vez recibe mayor número de contribuciones.

Un cordial saludo, y mil gracias por preferirnos.

Marisleidy Alba Cabañas, Ph. D.

Editora

\section{REFERENCIAS BIBLIOGRÁFICAS}

Alba, M. (2020). El infoconocimiento: una propuesta gerencial. Universidad Externado de Colombia.

Amshoff, B., Dülme, C., Echterfeld, J. \& Gausemeier, J. (2015). Business model patterns for disruptive technologies. International Journal of Innovation Management, 19 (3), 1540002. doi:10.1142/S1363919615400022. 
Bower, J. L., Christenson, C. M. (1995). Disruptive technologies: Catching the wave. Harvard Business Review, 73 (1), 43-53.

Brophy, W. (2015). Harnessing top talent in an era of disruptive technology, (4), 16-17. Retrieved from https://doi.org/10.4018/978-1-5225-9273-0.

Danneels, E. (2004). Disruptive technology reconsidered: A critique and research agenda. \&nbsp; J. Prod. Innov. Manag., 21 (4), 246-258.

Hui, Dawn S., mD Lee, Richard, mD мвA. (2016). Scan, plan, print, practice, perform: A disruptive technology? Journal of Thoracic and Cardiovascular Surgery, 153 (1), 141-142. doi:10.1016/j.jtcvs.2016.08.064.

Schuelke-Leech, B. (2018). A model for understanding the orders of magnitude of disruptive technologies. Technological Forecasting \& Social Change, 129, 261-274. doi:10.1016/ j.techfore.2017.09.033. 